\title{
Clarence Ayres, Ayresianos e a evolução do institucionalismo Vebleniano *
}

\author{
Ricardo Böck \\ Felipe Almeida ${ }^{* * *}$
}

\begin{abstract}
Resumo
O objetivo deste artigo é analisar a evolução do Institucionalismo de Thorstein Veblen por Clarence Ayres e o Cactus Branch. Veblen é um dos fundadores da Economia Institucional Original. Apesar da sua grande contribuição à Economia Institucional, a carreira acadêmica de Veblen foi errática. Ele não se estabeleceu em nenhuma universidade e não formou nenhum $\mathrm{PhD}$. Consequentemente, veblenianos tiveram pouco ou nenhum contato com Veblen. Dentre eles, Clarence Ayres é, certamente, um dos mais importantes. Diferentemente de Veblen, Ayres se estabeleceu na University of Texas, em Austin, e apresentou a tradição vebleniana para vários estudantes. O grupo institucionalista ayresiano ficou conhecido como Cactus Branch; no entanto, a perspectiva de Ayres sobre o Institucionalismo vebleniano é bem particular: o Institucionalismo ayresiano tem seu foco na dicotomia instrumentalcerimonial das instituições. A década de 1980 testemunhou uma redescoberta do Institucionalismo vebleniano. Institucionalistas do Cactus Branch desenvolveram uma versão do Institucionalismo ayresiano com mais ênfase em elementos veblenianos. Um segmento do Cactus Branch autodenominado Institucionalismo Radical recuperou a crítica social de Veblen em seus estudos.
\end{abstract}

Palavras-chave: Thorstein Veblen; Economia institucional; Economia institucional Original; Velha economia institucional; Cactus branch; Institucionalismo radical.

\section{Abstract \\ Clarence Ayres, Ayresians and an evolution of Veblenian institutionalism}

This paper analyzes the evolution of Thorstein Veblen's institutionalism by Clarence Ayres and the Cactus Branch. Veblen is a founding father of the Original Institutional Economics. Despite Veblen's contribution to institutional economics, his academic career was confusing. No university can be considered Veblen's "alma matter" and he did not tutor any PhD students. Hence, Veblenians had little or no contact with Veblen. Clarence Ayres is most definitely one of the most important Veblenians. Different from Veblen, Ayres made the University of Texas, at Austin, his academic home. He instructed several students on the Veblenian economics tradition. The Ayresian group of institucionalists became known as the Cactus Branch. However, Ayres held a particular perspective of Veblen's writings; Ayresian institutionalism focused on the instrumental-ceremonial dichotomy. The 1980s witnessed a rediscovery of Veblenian institucionalism. Institutionalists from the Cactus Branch introduced readings of Ayresian institutionalism closer to the Veblenian perspective. A segment of the Cactus Branch self-identified as Radical Institutionalists recovered Veblen's social criticism in their studies.

Keywords: Thorstein Veblen; Institutional economics; Original institutional economics; Old institutional economics; Cactus branch; Radical institutionalism.

JEL B15, B52.

\footnotetext{
*Artigo recebido em 18 de março de 2016 e aprovado em 25 de julho de 2017.

** Mestre pelo Programa de Pós-graduação em Desenvolvimento Econômico da Universidade Federal do Paraná (PPGDE-UFPR), Curitiba, PR, Brasil. E-mail: ricardoembock@gmail.com

*** Professor do Departamento de Economia da Universidade Federal do Paraná (UFPR), Curitiba, PR, Brasil. E-mail: felipe.almeida@ufpr.br.
} 


\section{Introdução}

Thorstein Veblen ocupa lugar de destaque na economia dissidente ou, em termos mais usuais, economia heterodoxa. De acordo com Lee (2009), as três principais vertentes que compõem a economia heterodoxa são o Marxismo, o PósKeynesianismo e o Institucionalismo Original; Veblen se associa à última. O Institucionalismo Original, Economia Institucional Original ou Velha Economia Institucional recebe os adjetivos "original" ou "velha" devido a uma busca por diferenciação de novas formulações teóricas, que alegam ser ou são classificadas como institucionalistas.

O termo Economia Institucional foi empregado em um texto científico pela primeira vez em Hamilton (1919). A Economia Institucional, como definida por Hamilton (1919), pode ser compreendida pela abordagem econômica que oferece explicações ao comportamento econômico baseado em instituições, hábitos e às suas evoluções (veja também Hodgson, 1998). Veblen foi um dos fundadores do Institucionalismo original, juntamente com John Commons, Wesley Mitchell e Clarence Ayres (Rutherford, 1994).

Os escritos de Veblen datam dos últimos anos do século XIX até as três primeiras décadas do século XX; esse autor trouxe novas ideias e contrapontos ao que era postulado pela ciência econômica à época, ciência esta, fortemente influenciada pela escola clássica e pelos desdobramentos recentes da escola neoclássica, especialmente os refinamentos realizados por Alfred Marshall. Para Veblen, a ciência econômica praticada era demasiadamente teleológica, o que julgava ser característico de uma ciência pré-evolucionária. Como alternativa, propunha que a ciência econômica fosse pensada em termos de processo, isto é, dando maior relevância ao processo econômico e menos a seus fins, o que caracterizaria uma ciência pós-evolucionária (Veblen, 1898, 1899a; veja também Cavalieri, 2015). Foi isso que Veblen buscou empreender em seus escritos.

Veblen foi um pesquisador crítico do sistema capitalista instaurado na sociedade estadunidense de sua época, contestando a forma com que os interesses pecuniários impunham suas vontades e valores à coletividade. Sendo assim, nutria parcas esperanças na formação de um corpo social em cujo arranjo institucional estivessem refletidos as necessidades e os anseios da ampla maioria da população. Ao contrário, o que se verificava era o fortalecimento de poucos, mas poderosos, interesses. Ainda assim, Veblen confiava na possibilidade de a tecnologia enfraquecer os interesses pecuniários em favor dos interesses industriais, modificando a institucionalidade vigente.

A despeito de tais questionamentos, o autor não trouxe respostas definitivas a como isso poderia ser feito, deixando essa área de pesquisa em aberto. Outros autores adentram a discussão dessa temática trazendo contribuições relevantes para 
o aprofundamento do debate. Identificar os descendentes intelectuais de Veblen é uma tarefa complexa. A trajetória acadêmica de Veblen é errática por demais. Veblen nunca ocupou cargo de representatividade acadêmica nas muitas universidades em que trabalhou, nunca obteve tenure e não formou um $\mathrm{PhD}$ (Dorfman, 1934).

Clarence Ayres, um dos principais expoentes dissidentes do século XX, se autointitulava vebleniano (Breit; Culbertson Jr., 1976; Coats, 1976). Diferentemente do nomadismo do seu mentor intelectual, Ayres desenvolveu suas atividades acadêmicas na University of Texas, em Austin. Ayres foi reconhecido à época como a principal voz do Institucionalismo dentro dos Estados Unidos, sendo responsável pela disseminação da tradição vebleniana. Ayres foi o líder intelectual do Cactus Branch, um segmento da Economia Institucional localizado no sudoeste estadunidense (Report On Interviews with American Economists, 1963; arquivos de Allan Gruchy; arquivos de John Gambs e Sturgeon, 1981).

O Cactus Branch buscou desenvolver a perspectiva ayresiana dos escritos de Veblen, a saber, análise da importância da dicotomia entre os aspectos institucionais (cerimoniais) e tecnológicos (instrumentais) para a abordagem do desenvolvimento econômico (Report On Interviews with American Economists, 1963; arquivos de Allan Gruchy e arquivos de John Gambs). Outros expoentes representativos do Cactus Branch são J. Fagg Foster, John Hodges, David Hamilton, Mark Tool, Louis Junker, Paul Dale Bush e F. Gregory Hayden.

Na década de 1980, PhDs formados por cactus branchers introduziram uma interpretação dos pontos centrais dos escritos de Veblen diferente da interpretação ayresiana. Essa nova interpretação se pautou na recuperação da crítica social contida nas obras de Veblen e ficou conhecida como Institucionalismo Radical. O termo "radical" advém do mesmo emprego em Economia Política Radical - abordagem centrada no Marxismo (Dugger, 1988). Porém, diferentemente da Economia Política Radical, o Institucionalismo Radical não repousa na Teoria do Valor, mas na crítica social vebleniana. Os principais institucionalistas radicais são William Dugger, William Waller Jr., Rick Tilman e Howard Sherman.

A opção por abordar a evolução do Institucionalismo vebleniano como desenvolvimento teórico Veblen-Ayres/Cactus Branch-Institucionalismo Radical está na abordagem de grupos autoproclamados veblenianos. Esses grupos possuem as seguintes características: (1) preocupação de desenvolver o Institucionalismo vebleniano como elemento que une os seus membros; e (2) longevidade (para que possam ser já enquadrados como elementos de uma lógica evolucionária).

Obviamente, dada a grande representatividade dos escritos de Veblen, Ayres não foi o único que buscou dar continuidade ao Institucionalismo vebleniano. Wesley Mitchell, Robert Hoxie e John Maurice Clarck também buscaram 
desenvolver a teoria de Veblen, mas abandonaram esse objeto de pesquisa (Rutherford 1998; Hodgson, 2004a, cap. 12). Por isso, o presente artigo não aborda tais autores, o que não sugere que eles sejam menos importantes.

O objetivo deste artigo é apresentar como o Institucionalismo vebleniano foi desenvolvido por Clarence Ayres, o Cactus Branch e o Institucionalismo Radical. Para alcançar tal objetivo, este texto é subdividido em mais cinco seções. O item dois traz os principais elementos do Institucionalismo, como apresentados por Veblen. $\mathrm{O}$ tópico três introduz o desenvolvimento do Institucionalismo vebleniano pelos escritos de Ayres e dos cactus branchers. A seção quatro enfatiza o desenvolvimento do Veblenianismo por meio do Institucionalismo Radical. O item cinco diz respeito aos principais debates entre cactus branchers e institucionalistas radicais visando delinear convergências e divergências entre as diferentes linhagens de institucionalistas veblenianos. O tópico seis apresenta a história organizacional do Institucionalismo do período pós-guerra até a década de 1980, visando enfatizar o pano de fundo histórico do conteúdo analisado. Por fim, as considerações finais.

\section{$2 \mathrm{O}$ institucionalismo de Thorstein Veblen}

Em seu primeiro livro, The Theory of the Leisure Class (1899b), Veblen reinterpreta a lógica do consumo com base na influência exercida pela elite socioeconômica sobre a tomada de decisão do consumidor, embora tal influência não se limite somente ao consumo, considerando as obras de Veblen como um todo (e não somente The Theory of the Leisure Class). Ele ironicamente denomina a elite socioeconômica como "classe ociosa", classe social que surge da diferenciação evolucionariamente estabelecida entre as diversas atividades sociais. Essa classe se furta de atividades laboriosas e industriais, relegadas às classes inferiores; essa é uma forma de expressar sua superioridade pecuniária (Veblen, 1899b). Estando no topo da escala social, suas preferências de consumo, maneiras de ser e costumes são emulados pelas demais classes logo abaixo na escala social. O consumo também é uma forma de a classe ociosa demonstrar superioridade pecuniária ${ }^{1}$. Essa emulação encontra-se no cerne dos hábitos de pensamento socialmente disseminados.

Hodgson (1998) define o conceito vebleniano de hábito como uma propensão amplamente não deliberativa e largamente automatizada à adoção de um padrão de pensamento ou comportamento. Na perspectiva vebleniana, um hábito não necessariamente significa comportamento, embora alguns se apresentem dessa forma; um hábito é um comportamento potencial que pode ser desencadeado por determinado estímulo ou contexto (Hodgson, 2002; 2004b). Adicionalmente, um hábito pode estar associado à ausência de comportamento. Na perspectiva

(1) Shipman (2004) apresenta o consumidor conspícuo vebleniano de forma bastante clara ao enfatizar que se trata de um consumidor guiado pela demonstração social da sua capacidade de "gasto" e não "gosto" individualmente estabelecido. O consumidor conspícuo vebleniano emula pecuniariamente o status da classe ociosa. 
vebleniana, as conceituações de hábitos e instituições se confundem, pois as instituições são desdobramentos dos hábitos socialmente compartilhados (Veblen, 1909; 1919). A abordagem vebleniana está centrada em instituições mediando a evolução de pensamentos e comportamentos. O evolucionismo vebleniano diz respeito ao estabelecimento de hábitos e instituições do passado que condicionam questões sociais do presente e que, por conseguinte, condicionarão pensamentos e comportamento futuros. A evolução vebleniana não implica necessariamente melhora ou cenário mais eficiente; trata-se de uma modificação cumulativa.

Veblen (1899b) afirma que instituições e hábitos contêm grande teor cerimonial. Na perspectiva vebleniana, o cerimonial pode ser entendido como aquilo que é socialmente aceitável e não carrega consigo aspectos tecnológicos relevantes. O cerimonialismo é aquilo que é socialmente criado; está no cerne dos costumes que imperam em determinada comunidade. Logo, o cerimonialismo é uma característica à qual qualquer instituição está exposta. Em The Theory of the Leisure Class, Veblen associa o cerimonialismo ao papel exercido pela classe ociosa. Pelo posicionamento social, a classe ociosa dita costumes que se tornam habitualmente enraizados na sociedade, revelando um balanço desigual de poder socioeconômico cerimonialmente estabelecido.

Em The Theory of Business Enterprise (1906), o foco de Veblen não mais é uma crítica ao cerimonialismo, à elite e ao consumo, mas à influência da lógica de negócios na estrutura social. Para ele, o ponto de vista dos negócios dita a dinâmica socioeconômica e condiciona os hábitos de pensamento vigentes (Veblen, 1906). Uma vez que é a interação entre os diversos processos industriais que estabelece a direção do ambiente de negócios (Veblen, 1906) e que este engloba instituições importantes e influentes no corpo social, sendo conduzido por empreendedores que atuam em processos industriais, o controle da estrutura de negócios pode ser usado por esses empresários em favor próprio.

Para Veblen (1906), a maior fonte de ganhos pecuniários corresponde ao controle da estrutura de negócios e não à esfera produtiva em si, pois nela apenas se realizam tais ganhos; todavia, isso não significa que a esfera produtiva seja insignificante, mas sim que ela é condicionada por tais fatores. Ao mesmo tempo, há demanda empresarial por maior precisão e produtividade nos processos industriais, materializável a partir de aprimoramentos técnicos. Esses aperfeiçoamentos são possíveis via avanços tecnológicos, que Veblen coloca como vetores de mudança viabilizados por meio do trabalho de inventores e engenheiros ${ }^{2}$. Portanto, a tecnologia é um fator de mudança capaz de ser desenvolvido no núcleo da sociedade por indivíduos que participam dela. A tecnologia é um componente substancial nas

(2) Essa é uma ideia incipiente em The Theory of the Leisure Class (1899b) e mais bem desenvolvida em The Theory of Business Enterprise (1906). 
interpretações dos escritos de Veblen, sendo sugerida muitas vezes como oposta ao componente cerimonial ${ }^{3}$.

Na opinião de Veblen, o processo de inovação tecnológica ocorre em uma estrutura institucional já existente, não havendo modificação abrupta e sim adaptações do esquema existente causadas pelo uso de novas tecnologias (Rutherford, 1984); ele denomina esse fenômeno como "adequação cerimonial" (Veblen, 1899b). É em virtude de tais fatores que os avanços técnicos não são prontamente assimilados. A adequação cerimonial conserva o ambiente institucional vigente frente à mudança tecnológica. No entanto, novidades tecnológicas podem abrir precedentes a outras inovações e modificar as instituições. Refinamentos tecnológicos frequentemente possibilitam a melhora da vida material dos indivíduos, novas facilidades materiais são capazes de modificar os hábitos vigentes e produzir certas maneiras de agir e pensar que podem acarretar novos costumes e posteriormente assumir formato institucional, institucionalidade esta, capaz de influenciar as predisposições futuras a novas configurações tecnológicas (Rutherford, 1984). Logo, a interação entre as instituições e a tecnologia pode produzir resultados diferentes: nova tecnologia, nova instituição, ambas ou nenhuma.

Assim, na perspectiva vebleniana, tanto a mudança tecnológica como os comportamentos cerimoniais incrustados em instituições são elementos centrais ao processo de mudança institucional. É interessante notar o recorte analítico fornecido ao papel das instituições e a tecnologia nos escritos de Veblen. Em The Theory of the Leisure Class, Veblen trabalha a evolução social das instituições, dando ênfase a como elas são influenciadas pelos costumes e pela herança cultural, aspectos de caráter cerimonial. Também é notável como em The Theory of Business Enterprise a influência da dinâmica de negócios na estrutura social é altamente condicionada pela fronteira tecnológica. Colocados lado a lado, o aspecto dicotômico fica mais evidente.

Veblen não apresenta com rigor alguma explicação que mostre como tal processo condiciona os aspectos cerimoniais envolvidos pelas instituições, embora aponte que modificações nas instituições ocorram através da continuidade do processo tecnológico. Essa questão foi notada por Clarence Ayres, que durante a primeira metade do século XX prosseguiu investigando o processo de mudança tecnológica, incorporando algumas ideias já discutidas por Veblen e outras advindas da Filosofia pragmática de John Dewey, a quem Veblen também recorria, ampliando o escopo de análise. Cabe a observação de que Thorstein Veblen não elaborou uma teoria da mudança institucional, estabelecendo conceitos e articulando ideias que em

(3) Louis Junker interpreta assim essa oposição: "Veblen conceived of the cultural process as having two basic aspects, or forms, or types of behavior patterns, the one being technological and the other institutional. The technological aspect or type of behavior is the dynamic aspect of culture" (Junker, 1968, p. 204). 
conjunto formatassem uma estrutura conceitual interligada entre si, visto que não dá foco à formalização de questões conceituais. Em virtude disso, parte significante de sua produção sobre o processo de mudança institucional se desenvolve em nível dissertativo-abstrato. Cientes disso, os intérpretes veblenianos do Cactus Branch retomam e reformulam ideias já presentes nos escritos de Veblen, buscando organizá-las de forma sistemática, com o propósito de conectar os elementos que se relacionam dentro do processo institucional.

\section{Clarence Ayres e o Cactus Branch}

Clarence Ayres foi o líder carismático e pai fundador do Cactus Branch. O foco central dos escritos de Ayres repousa na discussão do caráter instrumental (tecnológico) $)^{4}$ e cerimonial das instituições ${ }^{5}$. O grande ponto do Institucionalismo ayresiano é se aprofundar em uma dicotomia com a qual Veblen apenas flertou, a dicotomia cerimonial-instrumental. $\mathrm{Na}$ análise ayresiana, a tecnologia representa o instrumentalismo, e a principal característica da tecnologia é sua natureza inerentemente progressiva. Dessa forma, para Ayres, uma nova tecnologia sempre é superior à tecnologia imediatamente anterior. O entendimento de que a civilização havia atingido um estágio bastante fértil de inovações e eficiência técnica parece despertar em Ayres a noção de que tais elementos sejam preponderantes na análise de um sistema econômico (Ayres, 1935).

Também é importante destacar que Ayres não analisa a tecnologia a partir de um purismo técnico ou em uma perspectiva individualizada; pelo contrário, Ayres enfatiza a tecnologia como um produto social (Ayres, 1944). Ao considerar a tecnologia um produto social, temos que a compreensão ayresiana do processo instrumental leva em consideração a interação indissociável entre habilidades e ferramentas no âmbito social e a tecnologia é passível de avanços progressivos por meio da combinação de ferramentas. Ao perceber a tecnologia como desenvolvimento social, Ayres analisa as invenções como produtos específicos de determinado período histórico; no entanto, mesmo considerando o caráter inevitavelmente progressivo da tecnologia, há de se ressalvar que novas tecnologias requerem aceitação social (Ayres, 1944).

(4) Membros do Cactus Branch passaram a considerar o processo tecnológico como um processo instrumental. O instrumentalismo passou a ser dicotomicamente definido como o oposto ao cerimonialismo.

(5) Em relação ao método científico evolucionário, Ayres enfatiza com mais robustez muitas concepções trazidas à tona por Veblen, como o uso da Psicologia Social no fazer científico (Ayres, 1918a). Uma consequência direta disso é a maior evidência que Ayres forneceu ao papel das instituições em suas explicações tanto do processo de evolução social como de transformação econômica, em decorrência da ideia de que o pensamento dos homens é muito mais condicionado pelo ambiente social no qual estão inseridos do que por suas próprias ações individuais (Ayres, 1921a; 1921b; 1944; 1951). Outro ponto comum entre Veblen e Ayres é a visão de que a estrutura econômica da sociedade moderna é dominada pelo processo mecânico industrial (Ayres, 1918b), que dita regras e é capaz de afetar o funcionamento do sistema econômico, causando distúrbios. 
Considerando a contraparte da dicotomia, temos o cerimonialismo. Ayres (1944) constata que comportamentos cerimoniais não só são antitecnológicos como pseudotecnológicos, pois o componente cerimonial é inibidor do progresso tecnológico. Ayres conceitua instituições como segmentos de comportamento social predominantemente cerimoniais em caráter (Ayres, 1944). Logo, para ele, as instituições são os vetores de transmissão dos comportamentos cerimoniais ao longo do tempo, inibindo avanços de ordem instrumental. Na opinião de Ayres, é necessário compreender por que o processo cerimonial é vinculado ao passado (hábitos e costumes) e como suas características interagem de modo a tornar seu caráter inibitório mais inteligível (Ayres, 1961).

De acordo com Ayres (1961), práticas cerimoniais e instrumentais coexistem, servindo cada qual a determinadas funções. Como consequência de tal coexistência, um elemento valorativo é evocado e há distinção entre valores instrumentais e valores cerimoniais, pois há um pano de fundo que motiva as razões pelas quais práticas cerimoniais ou instrumentais são adotadas. Para Ayres, tal pano de fundo é dado pela estrutura de valores. Ele enfatiza que é dentro do processo tecnológico que se manifestam os mecanismos que revelam o que ele denomina "valores verdadeiros"6 de uma sociedade (Ayres, 1942). Sendo assim, o escopo teórico ayresiano pretende expressar a ordem social como fruto da inter-relação entre o cerimonialismo e o instrumentalismo e revelar como foi trilhado o processo evolutivo dos sistemas de valores vigentes em cada período. Para Ayres, o desenvolvimento econômico se pautava no desenvolvimento de valores instrumentais.

Os escritos de Ayres foram objeto de inúmeros estudos; é possível notar que a perspectiva ayresiana é utilizada desde o tratamento de questões específicas (tal como em Gordon, 1973) até a formatação de estruturas conceituais mais complexas (vide Foster, 1981a; 1981b; Bush, 1983), que pretendem abarcar as especificidades que surgem no processo de evolução social. Há inclusive a busca de aplicação empírica (vide Bush, 1983; 1987; Hickerson, 1983; O'Hara, 1997), porém são mais recorrentes os levantamentos de questões pontuais eventualmente deixadas em aberto por Ayres e que fazem parte da própria agenda de pesquisa da escola institucionalista (vide Rutherford, 1981; De Gregori, 1977; Mayhew, 1981).

Aluno de Ayres, J. Fagg Foster foi outro institucionalista que buscou investigar o processo de valoração por meio da perspectiva instrumental, sobretudo a questão tecnológica e seus desdobramentos práticos relacionados à resolução efetiva de problemas econômicos reais ${ }^{7}$. Embora suas investigações orbitem a

(6) Dessa forma, tais valores são tratados de forma científica e não metafísica (Ayres, 1942).

(7) Dado que parcela substancial da produção de Foster foi disseminada pela tradição oral, o resgate de suas contribuições foi realizado num momento posterior à sua realização. Muito disso se deve a Mark Tool e à publicação especial de seus escritos no Journal of Economic Issues de dezembro de 1981. 
temática de seu mestre, Foster é dono de contribuições genuínas. Seu ideário parte de um escrutínio metodológico, no intuito de identificar as principais diferenças entre John Dewey, Veblen e o próprio Ayres no que diz respeito ao valor.

De acordo com Foster, seguindo a linha ayresiana, o progresso econômico é capitaneado pelo processo tecnológico, dentro do qual se buscam mecanismos efetivos de resolução de problemas econômicos reais para aprimorar o padrão de vida da comunidade. Essa busca é contínua, uma vez que os problemas econômicos emergem à medida que as ferramentas e os intelectos - onde se expressam os arranjos institucionais - disponíveis deixam de ser eficientes na provisão dos meios de vida à comunidade (Foster, 1981b). É por meio de tal processo que o valor econômico emerge, sendo uma expressão daquilo que é economicamente estimado (valorado) dentro da sociedade, que na lógica instrumental é a eficiência técnica. Para Foster, são necessárias modificações nos padrões comportamentais institucionalizados para que os problemas econômicos sejam sanados pela modificação instrumental. Em virtude dessa percepção, Foster chama a atenção para a necessidade de um ajuste institucional que proporcione a resolução de problemas (Foster, 1981b).

Paul Dale Bush, aluno de Foster, seguiu os passos de seu professor e buscou sistematizar a lógica da valoração para o Cactus Institutionalism. A noção de valores, para Bush (1983; 1987), é determinada mais pela sua funcionalidade dentro do sistema institucional do que por seu conceito propriamente dito. Para Bush, valores funcionam como padrões de julgamento pelos quais o comportamento é correlacionado tanto dentro de um padrão comportamental como entre distintos padrões comportamentais. Assim sendo, é o sistema de valores da instituição que estabelece a inter-relação funcional de todos os padrões de comportamento internos àquela instituição (Bush, 1987). Seguindo a tradição de Veblen e Ayres, Bush (1983; 1987) considera a estrutura institucional incorporando dois sistemas de valores distintos - o cerimonial e o instrumental - utilizando em sua análise a dicotomia cerimonialismo-instrumentalismo.

Conceitualmente, Bush $(1983 ;$ 1987) se refere a padrões comportamentais "cerimonialmente garantidos" e "instrumentalmente garantidos" (BUSH, 1983; 1987). Esse autor nota a dialética no comportamento como um elemento que complexifica a análise de padrões comportamentais e dificulta a identificação dos valores, pois pode haver interação entre comportamentos cerimoniais e instrumentais. Nesse caso, a correlação comportamental depende do valor que define o padrão comportamental (Bush, 1987). Contudo, uma observação importante é que os padrões comportamentais instrumentalmente garantidos estão limitados à capacidade racionalizável, ou seja, não são capazes de racionalizar padrões puramente cerimoniais e estão condicionados à esfera da resolução de problemas envolvendo ferramentas e habilidades (Bush, 1987). 
Em contrapartida, os padrões cerimonialmente garantidos são ilimitados, pois aceitam toda sorte de argumentos, desde que esquematizados de maneira plausível. Há também casos em que o comportamento instrumental é "encapsulado" por um padrão comportamental cerimonialmente garantido (Bush, 1987). O encapsulamento cerimonial é um processo no qual a estrutura institucional até pode absorver nova tecnologia, mas sem que haja modificação em sua estrutura de valores $^{8}$ (Bush, 1983; 1987). Sendo assim, tal padrão comportamental cerimonialmente prescrito terá incorporado o comportamento instrumental, mantendo incólume a estrutura de valores. Tal encapsulamento leva à conceituação de dominância cerimonial, em que as variáveis instrumentais são dominadas pelo padrão de adequação cerimonial. Dessa perspectiva, Bush (1987) concebe o índice de dominância cerimonial, que estabelece uma relação inversa entre o surgimento de novas tecnologias e a permissividade das práticas cerimoniais, isto é, quanto maior for o índice de dominância cerimonial, menor será a permissividade institucional frente às inovações tecnológicas - e vice-versa.

Quando trata do encapsulamento cerimonial e das questões que o envolvem, Bush (1987) leva em consideração algumas ponderações propostas por Louis Junker (1982; 1983), que chama a atenção para as características contemporâneas do cerimonialismo e o papel que a tecnologia exerce para romper as barreiras cerimoniais. Segundo Junker (1982), é necessária uma apreciação crítica sobre a utilização da dicotomia cerimonialismo-instrumentalismo pelos próprios autores da escola institucionalista. De acordo com ele, a escola deve mudar seu enfoque na mera distinção entre esses aspectos e centrar-se num debate mais profundo que, além de incorporar as mudanças na dinâmica social capitaneadas pelos interesses pecuniários, seja capaz de transformá-la. Uma sugestão é revisar o papel da tecnologia e do cerimonialismo num ambiente institucional em constante modificação, diferenciando forças tecnológicas genuínas de forças tecnológicas espúrias, que inibem alterações no status quo.

Sendo assim, Junker coloca as funções cerimoniais de maneira diversa a Ayres, pontuando que elas servem, sim, a funções específicas dentro da sociedade, como legitimar o exercício da dominação: "[ceremonial behavior functions] serve a larger purpose - they serve to justify and legitimize the domination of particular control systems and groups over real technological developments" (Junker, 1982, p. 144). Prosseguindo nessa linha, Junker (1983) estabelece a "reconstrução" da dicotomia instrumentalismo-cerimonialismo de forma mais ampla e genérica ao fornecer o conceito de relações tecnológicas e expandir o entendimento do cerimonialismo para relações de poder instituídas por grupos influentes.

(8) O encapsulamento cerimonial não necessariamente acontece sobre a tecnologia em si, pois pode haver um encapsulamento de quaisquer padrões comportamentais. 
Percebe-se que os cactus branchers contemporâneos, como Bush e Junker, resgatam elementos veblenianos ausentes em Ayres e cactus branchers da primeira geração, como Foster: as análises de Ayres e Foster são fortemente focadas no papel instrumental da tecnologia. Para Ayres e Foster, a mudança institucional ensejada por avanços tecnológicos seria capaz de romper com o cerimonialismo presente na sociedade. Os estudos de Bush e Junker resgatam a importância do cerimonialismo como elemento central na constituição da sociedade, algo presente nos escritos de Veblen, para a análise institucional. De acordo com Bush e Junker, uma mudança institucional pode ser capitaneada ou encapsulada pelo cerimonialismo presente na sociedade.

\section{Institucionalismo radical}

A seção anterior destacou os escritos de cactus branchers contemporâneos que retomaram elementos veblenianos na exposição da dicotomia instrumentalismocerimonialismo tal como apresentada por Ayres e aperfeiçoada pela primeira geração do Cactus Institutionalism. Esta seção destaca que o resgate do conteúdo vebleniano pode ser compreendido como um movimento institucionalista dos anos 1980. Por um lado, alguns membros do Cactus Branch buscavam inserir Veblenianismo no Institucionalismo ayresiano. Por outro lado, alguns membros do mesmo grupo retomaram a crítica social presente nos escritos de Veblen ignorada por Ayres. A leitura contemporânea da crítica social vebleniana ficou conhecida como Institucionalismo Radical.

De acordo com Dugger (1988), o Institucionalismo Radical, assim como o Marxismo, é uma vertente teórica profundamente crítica ao capitalismo industrial. Entretanto, o Institucionalismo Radical difere do Marxismo porque não se apoia em uma teoria do valor e sim no Institucionalismo de Veblen"; já para Dugger e Waller (1996), a palavra "radical" qualificando o Institucionalismo significa uma volta ao Institucionalismo vebleniano. Na opinião de Waller (1988), o Institucionalismo Radical corresponde a uma análise crítica do sistema econômico com a intenção de propor um sistema que repouse sobre práticas e estruturas sociais mais democráticas e participativas. Segundo Dugger e Waller (1996), os institucionalistas radicais poderiam ser classificados como institucionalistas fundamentalistas que buscam estender a análise de Veblen para os dias atuais. Os institucionalistas radicais analisam a sociedade por meio de uma rede de instituições que podem definir padrões organizados aos papeis sociais associados

(9) Dugger (1988, p. 1) é explícito na menção a Veblen: "Radical institutionalism is the institutionalism of Thorstein Veblen". Apesar dessa grande menção a Veblen, Dugger destaca que os trabalhos de John Commons também são considerados pelo Institucionalismo Radical, embora com expressividade muito menor. Uma análise comparativa entre o Institucionalismo Radical e o Marxismo pode ser encontrada em Dugger e Sherman (1994). Um estudo sobre as associações e dissociações entre as noções de classes sociais para o Institucionalismo Radical e o Marxismo pode ser encontrada em Klein (1992). 
a determinados hábitos de pensamento. Tal associação, inclusive, determina como executar tais papéis/tarefas/atividades (Dugger, 1980).

De acordo com Dugger (1980, 1989), indivíduos presentes na mesma sociedade competem pelo exercício das funções sociais; essa competição está intimamente ligada à emulação social, tal como estabelecida por The Theory of the Leisure Class. Para Dugger (1989), a emulação é uma competição por status, uma rivalidade pessoal baseada na inveja, cujo ponto central é mostrar-se melhor que os demais competidores. O processo pelo qual isso ocorre é a aquisição de símbolos de status e a demonstração dessa aquisição para os demais. Nas palavras de Dugger (1989, p. 142): "[e]mulation distorts the culture as much as it distorts the individual'. Há uma clara diferença entre o conteúdo dessa passagem e a noção de emulação para Veblen (1899b), que enfatiza que a emulação é um produto institucional, é parte da cultura, não uma distorção, mas um componente da sociedade em questão. Consequentemente, os indivíduos internalizam esse conteúdo institucional; portanto, para Veblen (1899b) a emulação não é uma distorção, mas um aspecto institucional que compõe a tomada de decisão dos indivíduos.

Para Dugger (1989), a emulação é uma fonte de encapsulamento cerimonial, pois a busca por status migra facilmente entre instituições. O exemplo apresentado por esse autor é o líder corporativo, nos EUA no século XX como simbologia de sucesso que deve ser emulado, pois indivíduos fora do mundo corporativo passaram a emular tal indivíduo. Dessa forma, o prestígio do líder corporativo é encapsulado por instituições não corporativas. Para Dugger (1989), a emulação penetra nas coisas mais simples da vida. Dugger (1980) apresenta um simples exemplo que ilustra o encapsulamento cerimonial e a emulação nas coisas simples da vida: ele enfatiza que muitas vezes a família associa uma boa alimentação infantil com uma vida profissional de sucesso no futuro, algo como "filho(a), coma o seu café da manhã para ser um profissional tão bem-sucedido como o seu pai”.

O Institucionalismo Radical associa emulação e status ao poder, sendo este a habilidade de trabalhar com a cooperação alheia mesmo contra a opinião alheia (Dugger, 1980; 1988; Dugger \& Sherman, 1994). De acordo com Dugger (1980), qualquer análise institucional deve começar pela análise do poder. Em qualquer sociedade há uma estrutura institucional na qual os indivíduos estão inseridos; essa estrutura permite que alguns indivíduos exerçam poder sobre os demais (Dugger, 1980). Dugger \& Sherman (1994) enfatizam que as relações de poder são as mais importantes relações em uma sociedade. Tais relações já estavam presentes na sociedade mesmo antes das propriedades privadas, pois são prioritárias e fundadoras das sociedades tal como as conhecemos (Dugger; Sherman, 1994).

Para Dugger (1988), a origem do poder repousa no status, que é o prestígio reconhecido pelos outros; poder sem status é força e status sem poder é celebridade. É 
a associação entre status e poder que legitima socialmente a elite (Dugger, 1988). Status e poder separados são efêmeros, mas associados tornam-se extremamente sólidos (Dugger, 1988). Dugger (1980) destaca que o poder nem sempre se baseia em coerção, pois quando a coerção não é praticada, o poder mal é percebido; um exemplo disso seria o exercício de poder nos EUA no século XX, em que a coerção era mínima, pois o poder gerava segurança - exceto em períodos de crise ou guerra ${ }^{10}$ (Dugger, 1980).

Dugger (1989) afirma que a emulação é a principal forma de dominação, pois quando há emulação há exercício de poder sem coerção. A emulação implica a aceitação da estrutura social devido ao estabelecimento de metas de ascensão social. Nenhuma mudança social é demandada, pois o objetivo é ascender socialmente; logo, a estrutura social é preservada. Nesse contexto, a emulação mascara a injustiça social na forma de possibilidade de ascensão (Dugger, 1988). Para os institucionalistas radicais, a emulação se associa a símbolos criando mitos dentro de uma determinada sociedade, como "o sonho americano" (Dugger, 1980).

Os institucionalistas radicais lidam com a presença de mitos em um sistema socioeconômico, mitos que capacitam o estrato superior da sociedade a manter a sua posição socioeconômica (Dugger, 1988). Tais mitos estão associados à emulação executada pelas classes sociais que não as protegidas pelo mito. Para Dugger e Sherman (1994), os mitos fazem com que grupos com pior posicionamento social não compreendam os seus próprios interesses e sirvam aos interesses alheios. Mitos permitem que um grupo domine o outro sem coerção. Esses autores destacam que as relações de poder que geram mitos foram um dos focos principais dos trabalhos de Veblen. Dugger (1988) associa o mito e a emulação ao comportamento cerimonial que é utilizado para adquirir status e riqueza e justifica a posse de tais elementos.

Os institucionalistas radicais defendem que a emulação e a mitificação associadas à distorção e à contaminação geraram a hegemonia institucional da corporação ${ }^{11}$ (Dugger, 1980). A distorção está associada à incorporação do conteúdo de uma instituição (ou grupos de instituições) a outra instituição ou grupo. Para Dugger (1980), a distorção é o fenômeno institucional menos estudado, mas absolutamente fundamental para a análise institucionalista, pois destrói a perspectiva plural de qualquer sociedade. O melhor exemplo de distorção foi apresentado por Veblen em Higher Learning in America (1918); de acordo com Veblen (1918), as universidades estadunidenses estavam absorvendo o conhecimento técnico que os homens de negócio gostariam que os seus contratados possuíssem. Dessa forma, o

(10) Para Dugger (1988), o patriotismo e a emulação são os grandes protetores do status quo. A justificativa dessa afirmação repousa em uma lógica apresentada em The Theory of Business Enterprise, pois Veblen (1906) afirma que subserviência, obediência inquestionável, devoção e prorrogativas de classe são estabelecidas pelo patriotismo e atos de guerra.

(11) Distorção é uma tradução livre do termo subreption. 
conhecimento científico, tão caro às universidades, estava sendo substituído pelo conhecimento técnico relativo àquilo que era necessário e demandado pela corporação (Veblen, 1918).

A contaminação, por sua vez, diz respeito ao processo no qual os objetivos das funções sociais relacionadas a uma instituição se tornam objetivos das demais instituições, como instituições religiosas contaminadas por motivos pecuniários para fins de consumo conspícuo (Dugger, 1980). Retomando todos os elementos, temos: (1) a emulação gerando a aceitação e respeito dos líderes corporativos em meios não corporativos; (2) a contaminação inserindo motivos corporativos em funções sociais não corporativas; (3) a distorção conectando todas as instituições a corporações; e (4) a mitificação cobrindo a hegemonia corporativa pelos símbolos mais importantes da sociedade. Dessa forma, temos o poder corporativo não como um poder individual, mas como um poder institucional. Esse poder é mantido não somente pelos líderes corporativos privilegiados por tal instituição, mas por todos os indivíduos presentes na sociedade que exercem distintas funções sociais, que emulam e, consequentemente, protegem a hegemonia da corporação em toda a rede institucional presente na sociedade. Esse processo é, em grande parte, inconsciente. No centro dele há o mito de que qualquer indivíduo presente na sociedade consegue melhorar sua função e seu posicionamento social com o esforço. Cabe lembrar que os indivíduos não escolhem as suas funções sociais e são moldados por elas devido ao desempenho de hábitos de pensamento (Dugger, 1980).

\section{O debate Cactus Branch-Institucionalismo radical}

O desenvolvimento do Institucionalismo vebleniano pelas mãos de Ayres é um capítulo controverso na história do Institucionalismo. Malcolm Rutherford, um dos maiores historiadores das ideias institucionalistas, destaca que $\mathrm{o}$ Institucionalismo ayresiano repousa em duas premissas: (1) todos os objetivos e valores humanos se originam no processo instrumental; e (2) todos esses valores podem ser objetivamente definidos pela investigação tecnológico-científica (Rutherford, 1981). Esse autor destaca ainda que o maior empecilho metodológico dos escritos de Ayres é a clara distinção entre o cerimonial e o instrumental, questionando o tratamento cerimonial dado por Ayres a tudo aquilo que não fosse permeado pela dinâmica científico-tecnológica. Rutherford também destaca a visão deveras otimista do processo instrumental apresentada por Ayres como uma crítica.

Mesmo os cactus branchers não pouparam críticas aos escritos de Ayres. Anne Mayhew também nota esse "excessivo otimismo" na visão ayresiana do processo tecnológico e do progresso científico (Mayhew, 1981). Essa autora também traz à tona empecilhos ao progresso tecnológico que não são de natureza puramente cerimonial - como as restrições impostas pelo meio ambiente, os limites da sua exploração e o aumento da população. Thomas De Gregori critica o fato de Ayres 
afirmar que toda nova tecnologia é superior à anterior (De Gregori, 1977). Nesse contexto, as obras dos descendentes intelectuais de Ayres - como Foster e Bush podem ser interpretadas como tentativas de lidar com tais críticas (internas e externas ao Cactus Branch).

Do ponto de vista do Institucionalismo Radical, tais institucionalistas buscaram se afastar de Ayres e retomar o Institucionalismo mais crítico de Veblen (Dugger; Waller, 1996). Apesar da busca por um afastamento de Ayres, Dugger e Waller (1996) enfatizam que Ayres foi brilhante e importante para o Institucionalismo; no entanto, como sua abordagem evolucionária implica uma teoria do progresso, ela não permite uma expansão para a análise radical. Veblen, por outro lado, não acreditava em progresso, pois era um pessimista - enquanto Ayres era um otimista (Dugger; Waller, 1996). Ayres acreditava que o desenvolvimento tecnológico superaria as barreiras cerimoniais, Veblen não ${ }^{12}$.

Dugger (1988) destaca uma importante diferença da dicotomia instrumentalcerimonial para Veblen e para Ayres. Enquanto a dicotomia vebleniana foi estabelecida como uma crítica ao sistema capitalista, buscando enfatizar o absurdo do sistema, a dicotomia ayresiana se pauta na explicação de como instituições limitam a forma de fazer as coisas. Além disso, Dugger classifica a noção de progresso de Ayres como judaico-cristã: o indivíduo foi posto na Terra para subjugála e melhorá-la. Para Ayres, isso aconteceria por meio da tecnologia, mas tal processo poderia estar completamente dominado pelo cerimonialismo característico da resistência institucional.

Para Dugger e Waller (1996), o conhecimento instrumental está associado a como fazer as coisas, e o conhecimento cerimonial está associado ao motivo pelo qual as coisas são feitas - logo, há uma difícil dissociação. O conhecimento instrumental repousa sobre resolver problemas, e o conhecimento cerimonial vincula-se ao exercício de poder (Dugger; Waller, 1996). O instrumental se associa a fatos; o cerimonial, a prestígio (Dugger; Waller, 1996). Para esses autores, a resistência cerimonial é pautada em hábitos institucionalizados, crenças do passado, respeito pela autoridade e status. Por esse motivo, na história da humanidade o conhecimento cerimonial sempre triunfa sobre o conhecimento instrumental. Eles entendem que o poder e o prestígio que emanam do conhecimento cerimonial são importantes fontes de resistência à propagação do conhecimento instrumental. Essa é a perspectiva do Institucionalismo Radical. Os institucionalistas radicais responsabilizam o elitismo pela resistência cerimonial.

(12) Dugger e Sherman (1994) são mais duros com Ayres e seus seguidores: "[r]adical institutionalist emphasize the need to take collective action against ceremonialism, while liberal institutionalists see ceremonialism being weakened 'naturally' by the spread of education, enlightenment, and new technology" (p. 103). 
O tratamento da dicotomia pelos cactus branchers foi tema de um debate recente entre tal corrente institucional e o Institucionalismo Radical. Mayhew (1990) pode ser lido como uma reação de um membro do Cactus Branch sobre uma análise do Institucionalismo Radical acerca do Cactus Institutionalism - Waller (1988). Esse autor critica dois textos de cactus branchers, Hamilton (1986) e Mayhew (1987). A crítica de Waller (1988) repousa sobre uma suposta ausência de análise evolucionária em Hamilton (1986) e Mayhew (1987). De acordo com ele, as análises desses textos não correspondiam a uma análise evolucionária, pois não analisavam evolucionariamente como aspectos instrumentais e cerimoniais do comportamento institucionalizado se instauraram na sociedade. Mayhew (1990) contra-argumenta destacando que o ponto central de Hamilton (1986) é que estruturas sociais podem ser classificadas como instrumentais ou como cerimoniais, pois são ambas. Mayhew (1990) reconhece que o argumento-chave de Waller (1988) é a análise genuinamente institucional - pode-se ler vebleniana -, pois envolve a desagregação das instituições em aspectos instrumentais e cerimoniais.

Waller (1988) protesta contra a impossibilidade de separação instrumentalcerimonial, pois a não dissociação inviabilizaria a análise institucionalista radical. Para ele, o estudo agregado do instrumentalismo e do cerimonialismo gera a aceitação de objetivos cerimoniais e instrumentais presentes na sociedade. Waller (1990) é a tréplica da discussão que retoricamente destaca que o ponto central do debate não é uma discordância, mas uma falha de comunicação; enfatiza que Mayhew (1990) destaca que o instrumentalismo é um resultado de um processo institucional, mas não reflete um processo de valorização institucional específico. Waller (1990) concorda com Mayhew se este destacou que a validação instrumental não é objetivo da validação institucional. Note-se que essa argumentação foge do debate e reforça o ponto central de Waller (1988). Esse debate não é a primeira vez que o institucionalista radical William Waller Jr. criticou abordagens do Cactus Branch.

Waller (1987) apresenta fortes críticas ao conceito de encapsulamento cerimonial tal como desenvolvido pelo Cactus Branch, mais precisamente aos escritos de Bush. Waller (1987) enfatiza que a versão do Cactus Branch para o encapsulamento cerimonial apresenta a dicotomia vebleniana de forma confusa. Waller reconhece que essa é uma crítica forte, pois a dicotomia vebleniana é central no Institucionalismo desenvolvido pelo Cactus Branch. Waller (1987) destaca que a versão do Cactus Branch para a dicotomia está na lógica de que aspectos não cerimoniais sejam tecnológicos, sendo tal tecnologia passível de manifestação física, como no caso de ferramentas. Adicionalmente, Waller (1987) afirma que a hipótese do encapsulamento cerimonial não adiciona nenhum elemento analítico para o arcabouço institucionalista, pois os fenômenos que pretende analisar podem ser estudados por elementos da teoria institucional anteriores ao desenvolvimento dele. 
De acordo com Waller (1987), na perspectiva vebleniana as instituições filtram e adaptam os avanços tecnológicos em formas consistentes com seus valore $^{13}$, mas o encapsulamento cerimonial não segue essa lógica. Para esse autor, a emulação, a contaminação, a distorção e a mitificação, tal como assinaladas por Dugger (1980), destacam como a corporação se tornou a instituição dominante, subordinando todas as demais. Segundo ele, esse é o processo central que segue a análise estabelecida por Veblen. As descrições de encapsulamento cerimonial estariam contidas na esfera maior da dominância das instituições pela corporação. Isso forneceria à lógica do encapsulamento cerimonial as características de uma simples captura de tecnologia por uma instituição dominante (Waller, 1987).

Por fim, cabe destacar que, de acordo com Dugger e Waller (1996), o Institucionalismo Radical se difere do Institucionalismo ayresiano do Cactus Branch por trazer o Institucionalismo mais próximo para a discussão de valores sociais. No entanto, o Institucionalismo Radical não representaria uma quebra com o Cactus Institutionalism, mas uma tentativa de mover o Institucionalismo para além da fundamentação filosófica ayresiana (Dugger; Waller, 1996). Esse processo corresponderia à introdução de três elementos na perspectiva ayresiana: (1) fundamentos veblenianos; (2) uma modificação nos interesses de pesquisa; e (3) uma reconsideração na base filosófica da investigação científica. De acordo com Dugger e Waller (1996), há diferença entre valor para o Cactus Institutionalism e o Institucionalismo Radical. O primeiro foca o valor instrumental no processo tecnológico, enquanto o segundo analisa o foco de criação de valor como processo democrático. Ainda de acordo com esses autores, os institucionalistas radicais retomam a lógica instrumental como concebida por Veblen.

\section{0 contexto da retomada vebleniana na década de 1980}

Dado o conteúdo das seções anteriores, é possível notar, durante a década de 1980, o resgate dos elementos institucionalistas presentes nos escritos de Veblen. De um lado, Bush e Junker buscaram inserir Veblenianismo na abordagem ayresiana do Cactus Branch. Por outro, surgiu o Institucionalismo Radical, que resgata a crítica vebleniana. Dada a coincidência temporal, é válido destacar, mesmo que brevemente, a história da Economia Institucional do pós-guerra até a década de 1980. Assim é possível entender o contexto do resgate dos escritos originais de Veblen. Entender a essa história vincula-se fortemente a entender a sua organização em torno de duas associações: a Association for Evolutionary Economics e a Association for Institutional Thought.

(13) Waller (1987) destaca que Imperial Germany and the Industrial Revolution (1915) e Higher Learning in America (1918), de Veblen, são grandes exemplos de filtros e adaptações institucionais de acordo com valores, um processo institucionalmente mais complexo do que um encapsulamento cerimonial - como os livros estavam comumente sendo citados como exemplo por cactus branchers. 
Durante a década de 1950, os institucionalistas norte-americanos começaram a se organizar para lutar contra o claro declínio da Economia Institucional nos EUA. O resultado dessa organização foi a fundação, em 1965, da Association for Evolutionary Economics (AFEE), que pode ser compreendida como a institucionalização da organização de um grupo de institucionalistas autoproclamados Wardman Group ${ }^{14}$ (Bush, 1991; Gambs, 1980; O’Hara, 1995). O Wardman Group, por sua vez, surgiu de uma reunião de institucionalistas promovida por John Gambs e Allan Gruchy. A intenção deles era promover maior proximidade entre os institucionalistas veblenianos por meio de uma nova associação independente da American Economic Association - AEA (Gambs, 1980). Formalizar as ações conjuntas dos institucionalistas veblenianos, no final da década de 1950 e início da década de 1960, se mostrou consideravelmente complexo.

Tal complexidade está associada à linhagem econômica com a qual os membros da AFEE se identificavam. Lowe (1980) descreveu o Wardman Group como um emaranhado teórico. Lee (2009) apresentou uma hipótese para tal heterogeneidade: a AFEE foi a primeira associação dissidente da AEA. Logo, economistas insatisfeitos com a AEA interpretaram a AFEE como um potencial grupo de interlocutores. Seguindo essa lógica, o grupo foi além de somente institucionalistas veblenianos, como era a intenção original de Gambs e Gruchy. Rutherford (2015) destaca dois grupos bem definidos de economistas envolvidos com a fundação da AFEE: o Cactus Branch e os commonsianos ${ }^{15}$. Rutherford (2015) enfatiza também o que alega ser um terceiro grupo de mais difícil caracterização: seria composto pelo ayresiano Gambs, o vebleniano Gruchy, o keynesiano Dudley Dillard e o institucionalista-keynesiano ou keynesianoinstitucionalista John Kenneth Galbraith ${ }^{16}$. Gambs notou essa diversidade já na formação do Wardman Group. Nessa época, Gambs passou parte de um ano sabático

(14) O Wardman Group recebe esse nome devido à sua primeira reunião, que ocorreu em 1958, no Wardman Park Hotel em Washington, DC, EUA. Tal reunião ocorreu após o congresso da American Economic Association (AEA) em 1958; o mesmo foi verdade para os demais anos até a fundação da AFEE. O ponto central da reunião era unir os institucionalistas para resistir a um processo de exclusão. De acordo com eles, a economia neoclássica estava expulsando os institucionalistas das principais revistas acadêmicas e congressos nos EUA - como o congresso da AEA (Almeida, 2016). Cavalieri e Almeida (2015) também destacam que os institucionalistas sentiram que a Economia Institucional havia sido totalmente excluída dos principais programas de pós-graduação dos EUA durante o final da década de 1940 e na década de 1950.

(15) Os commonsianos são os descendentes intelectuais de John Commons, que, tal como Veblen, foi um pai fundador do Institucionalismo original. Dessa forma, a primeira segmentação do Institucionalismo original é dividida entre veblenianos e commonsianos. Como o foco do artigo é a evolução do primeiro, o último não foi analisado. Trata-se da definição do objeto de pesquisa e não possui nenhuma relação com a representatividade de John Commons para o surgimento da Economia Institucional, pelo contrário: Commons foi tão representativo quanto Veblen para o estabelecimento de tal escola de pensamento econômico.

(16) Hoje, a denominação institucionalista-keynesiano ou keynesiano-institucionalista pode não gerar estranhamento, pois é compreendido como uma aproximação entre duas importantes correntes heterodoxas. No entanto, no momento da fundação da AFEE, institucionalistas eram grandes críticos do keynesianismo (vide Cavalieri; Almeida, 2015; Whalen, 2016), embora se possa compreender que a crítica institucionalista focava muito mais no modelo Hicks-Hansen do que nos escritos de Keynes. 
viajando pelos EUA em busca de economistas interessados em fundar a nova associação.

Gambs identificou dois grupos de dissidentes interessados no grupo: veblenianos e não veblenianos. Além disso, destacou que havia grande margem de interpretação sobre o significado de ser vebleniano (Almeida, 2016). Outro ponto que reflete a não uniformidade teórica é o nome da associação. $\mathrm{O}$ nome faz menção à economia evolucionária, e não à Economia Institucional. Embora Gambs tenha destacado que o nome da associação era uma referência à forma como Veblen descrevia a sua economia (Sturgeon, 1981, p. 49), houve muito debate em torno do nome, inclusive rejeição ao termo Economia Institucional. Essa rejeição repousava na carga negativa que o termo passou a ter após anos de embate com a economia neoclássica (vide Almeida, 2016).

Apesar do grupo heterogêneo, a AFEE foi estabelecida com sucesso em 1965. No ano seguinte, a associação iniciou a publicação de sua revista acadêmica, Journal of Economic Issues (JEI). Os primeiros anos do JEI testemunharam grande instabilidade editorial, que terminou em 1971, quando Warren Samuels tornou-se o editor da revista (Almeida, 2016). Samuels foi um importante editor do JEI e iniciou a construção da reputação internacional da revista, mas trouxe de volta, enfaticamente, a discussão da orientação teórica da AFEE. Samuels foi um pluralista radical (vide Davis, 2012; Samuels, 1997; 2006); o pluralismo envolvia a aceitação da teoria neoclássica ${ }^{17}$. Esse pluralismo se refletiu nos artigos publicados pelo JEI. Dessa forma, Samuels permitiu que a revista da AFEE publicasse artigos que faziam menção aos motivos pelos quais a AFEE foi fundada. Obviamente, a atuação de Samuels como editor do JEI desagradou profundamente alguns membros da AFEE que acreditavam na associação como opositora à economia neoclássica. Um grande exemplo da presença neoclássica no JEI ocorreu no ano de 1975: dentre os quatro volumes anuais do JEI, dois foram dedicados à economia neoclássica; o volume de junho discutia o atual estado da economia ortodoxa e o volume de dezembro analisava a Escola da Chicago - naquele tempo eram muito comuns volumes temáticos no JEI. Nos dois volumes, a perspectiva analítica não repousava na tradição institucionalista, mas em uma perspectiva de história do pensamento econômico defendida por Samuels. Tanto Gambs quanto Gruchy se desligaram da AFEE em 1975. O ponto central do desligamento foi a AFEE ter se transformado em

(17) Em uma troca de cartas entre Ayres e Samuels, a aceitação da economia neoclássica pelo último fica evidente. Em 15 de agosto de 1968 (Arquivos do Clarence Ayres, Caixa 3F294), Ayres elogia a interpretação de Samuels sobre o Institucionalismo, mas critica o tratamento dado à economia neoclássica. O ponto de Samuels era: a economia neoclássica e o Institucionalismo poderiam se complementar. Para Ayres, tal era impossível, pois se tratava de abordagens totalmente diferentes em termos metodológicos e preocupações científicas. Por fim, Samuels chegou a enfatizar que se considerava um institucionalista com apreço pela economia neoclássica (27 de agosto de 1968, Arquivos do Clarence Ayres, Caixa 3F294). 
algo muito diferente do que Gambs e Gruchy tinham em mente originalmente (Almeida, 2016).

Institucionalistas do Cactus Branch também demonstraram sua insatisfação com as modificações ocorridas na AFEE durante os anos 1970. Essa insatisfação se materializou na fundação de outra associação, a Association for Institutional Thought (AFIT), em abril de 1979 (Sturgeon, 1981). Durante os debates para a fundação da nova associação, foi discutido se ela deveria ser independente ou uma segmentação da AFEE, optando-se, por fim, pela independência (AFIT, 1978; Sturgeon, 1981). O ponto central da nova associação institucionalista foi ter se afastado do mainstream do Institucionalismo. Uma grande mudança na AFEE ocorreu pouco tempo após a fundação da AFIT: em 1981, Samuels deixou o cargo de editor do JEI.

Marc Tool assumiu a editoria; Tool, um cactus brancher, foi o responsável por resgatar o Institucionalismo no principal veículo de divulgação de estudos institucionais, o JEI, durante a década de 1980. A editoração de Tool foi marcada por essa busca, e sua grande marca foram os volumes de setembro e dezembro de 1987 do JEI. Eles foram chamados de Evolutionary Economics I e II e mais tarde publicados como o livro Evolutionary Economics: Foundation of Institutional Thought, Volume I e Evolutionary Economics: Foundation of Institutional Thought, Volume II.

Dessa forma, a história organizacional da Economia Institucional na segunda metade do século XX mostra um ambiente de indefinição sobre seu futuro nos EUA. Um ayresiano, John Gambs, e um vebleniano, Allan Gruchy, adotaram ações em prol da organização dos institucionalistas, o que culminou na fundação da AFEE. No entanto, mesmo em um grupo rotulado "Economia Institucional" havia uma grande heterogeneidade, que resultou na fundação de outra associação institucional, a AFIT, apenas quatorze anos após a primeira associação. A década de 1980 se iniciou com a institucionalização da AFIT e uma nova editora do JEI. Nesse momento, iniciouse a busca pela compreensão do que significava o Institucionalismo original. Nessa busca, houve uma revisão do Institucionalismo ayresiano e o surgimento do Institucionalismo Radical.

\section{Considerações finais}

Thorstein Veblen foi um pensador essencial para a ciência econômica na virada do século XIX para o XX. A Veblen atribui-se o título de pai fundador do Institucionalismo original. Seus escritos foram norteados pela crítica social do sistema capitalista industrial associada a uma análise evolucionária que se baseia na importância de hábitos e instituições na tomada de decisão. Apesar da grande representatividade dos escritos de Veblen, o institucionalista não ocupou nenhum 
cargo de importância nas muitas universidades nas quais trabalhou. Dessa forma, Veblen não participou da formação de seus descendentes intelectuais. Os veblenianos não foram alunos de Veblen, mas pensadores preocupados em dar continuidade à sua obra e, consequentemente, à Economia Institucional.

Clarence Ayres é um dos mais importantes veblenianos. Ayres focou seus escritos no desenvolvimento da dicotomia cerimonial-instrumental, alegadamente presente nos escritos de Veblen. De fato, Veblen destaca a relação entre a tecnologia - elemento batizado como instrumental por Ayres - e procedimentos institucionalizados - que Ayres denomina cerimoniais, denominação também utilizada por Veblen. No entanto, Ayres apresenta uma leitura específica dos escritos veblenianos. Ele enfatiza que toda mudança instrumental é uma evolução progressiva da tecnologia, e o cerimonialismo representaria uma barreira ao positivo desenvolvimento tecnológico. Diferentemente de Veblen, Ayres desenvolveu suas atividades acadêmicas na University of Texas, em Austin, e tornou-se o líder de um grupo de institucionalistas que ficou conhecido como Cactus Branch. Os cactus branchers focaram seus esforços no desenvolvimento do Institucionalismo ayresiano.

Durante o Pós-Guerra, institucionalistas tentaram se organizar como grupo, pois perceberam um movimento de exclusão acadêmica devido ao forte processo de mainstreaming da economia neoclássica. Essa organização culminou em uma importante constatação sobre o Institucionalismo na segunda metade do século XX: não se tratava de um movimento homogêneo, havia uma série de interpretações sobre (1) o que significava ser institucionalista; e (2) os escritos de Veblen. Como consequência, na década de 1980 houve uma redescoberta dos escritos veblenianos por parte dos institucionalistas. Essa redescoberta resultou em duas frentes diferentes de desenvolvimento de estudos institucionalistas: (1) o Cactus Branch, que deu foco na busca pela inserção de mais elementos veblenianos nos escritos do Institucionalismo de Ayres; e (2) uma dissidência do Cactus Branch, o Institucionalismo Radical, que buscou transpor a crítica social vebleniana - algo esquecido por Ayres - para o século XX.

Por fim, cabe destacar que o presente artigo analisa apenas parcialmente a evolução do Institucionalismo vebleniano. A parcialidade se deve a uma análise direcionada a dois diferentes grupos de institucionalistas, o Cactus Branch e o Institucionalismo Radical. Ao longo do século XX, também houve leituras e contribuições individuais ao Institucionalismo vebleniano. Institucionalistas contemporâneos a Ayres - Wesley Mitchell, Robert Hoxie e John Maurice Clarck também buscaram desenvolver o Institucionalismo vebleniano, mas desistiram da tarefa. As desistências não tornam as suas obras menos importantes, mas não construíram um legado para o Institucionalismo vebleniano. 
Em termos de agrupamentos em associações, existem associações além da AFEE e AFIT nas quais se pode encontrar veblenianos entre seus membros, como a European Association for Evolutionary Political Economy (EAEPE), a Association for Social Economics (ASE) e a recém-fundada World Interdisciplinary Network for Institutional Research (WINIR). No entanto, essas organizações não representam um agrupamento em torno do desenvolvimento do Institucionalismo vebleniano. Por isso, não figuraram neste texto, mas cabe destacar que são associações de suma importância para o pensamento heterodoxo.

\section{Coleções de arquivos consultadas}

Arquivos de Allan Gruchy, de posse do saudoso Prof. Fred Lee e do Prof. Malcolm Rutherford.

Arquivos do Clarence Ayres Papers. Briscoe Center for American History. University of Texas, em Austin, Austin, Texas, EUA.

Arquivos de John Gambs, Hamilton College, Clinton, Nova York, EUA.

\section{Referências bibliográficas}

AFIT (Association for Institutional Thought). AFIT Report to AFEE. 1978. Disponível em: http://associationforinstitutionalthought.org/downloads/about/ AFIT-Report-AFEE. Acesso em: 12 jun. 2015.

ALMEIDA, F. Inside the organizational institutions of institutional economics: why are there two institutionalist associations? Journal of Economic Issues, v. 50, n. 2, p. 566-574, 2016.

AYRES, C. The epistemological significance of social psychology. The Journal of Philosophy, Psychology and Scientific Methods, v. 15, n. 2, p. 35-44, 1918a.

AYRES, C. The function and problems of economic theory. Journal of Political Economy, v. 26, n. 1, p. 69-90, 1918b.

AYRES, C. Instinct and capacity I: the instinct of belief-in-instinct. The Journal of Philosophy, v. 18, n. 21, p. 561-565, 1921a.

AYRES, C. Instinct and capacity II: homo domesticus. The Journal of Philosophy, v. 18 , n. 22, p. 600-606, 1921 b.

AYRES, C. Moral confusion in economics. International Journal of Ethics, v. 45, n. 2, p. 170-199, 1935.

AYRES, C. Economic value and scientific synthesis. The American Journal of Economics and Sociology, v. 1, n. 4, p. 343-360, 1942. 
AYRES, C. The theory of economic progress. The University of North Carolina Press. 1944.

AYRES, C. The co-ordinates of institutionalism. The American Economic Review. Papers and Proceedings of the Sixty-third Annual Meeting of the American Economic Association, v. 41, n. 2, p. 47-55, 1951.

AYRES, C. Toward a reasonable society: the values of industrial civilization. Austin University of Texas Press. 1961.

BUSH, P. D. An exploration of the structural characteristics of a Veblen-AyresFoster defined institutional domain. Journal of Economic Issues, v. 17, n. 1, p. 35$62,1983$.

BUSH, P. The theory of institutional change. Journal of Economic Issues, v. 21, n. 3, p. 1075-1116, 1987.

BUSH, P. Reflections on the twenty-fifth anniversary of AFEE: philosophical and methodological issues in institutional economics. Journal of Economic Issues, v. 25, n. 2, p. 321-346, 1991.

BREIT, W.; CULBERTSON JR. Clarence Edwin Ayres: an intellectual's portrait. In: BREIT, W.; CULBERTSON JR. Science and ceremony: the institutional economics of C. E. Ayres. University of Texas Press, Austin e London, 1976.

CAVALIERI, M. Thorstein Veblen entre seus pares economistas: um estudo sobre a audiência e a estrutura argumentativa de sua crítica sistemática ao pensamento econômico. Nova Economia, v. 25, p. 389-412, 2015.

CAVALIERI, M.; ALMEIDA, F. Institutionalists as dissenters: why were institutionalists so dissatisfied with economics during the post-war period. Journal of Economic Issues, v. 49, n. 2, p. 475-482, 2015.

COATES, A. W. Clarence Ayres's place in the history of American economics: an interim assessment. In: BREIT, W.; CULBERTSON JR. Science and ceremony: the institutional economics of C. E. Ayres. Austin; London: University of Texas Press, 1976.

DAVIS, J. Samuels on methodological pluralism in economics. Disponível na SSRN: http://papers.ssrn.com/sol3/papers.cfm?abstract id=2013585. Acesso em: 23 out. 2015.

DE GREGORI, T. Technology and ceremonial behavior: aspects of Institutionalism. Journal of Economic Issues, v. 11, n. 4, p. 861-870, 1977.

DORFMAN, J. Thorstein Veblen and his America. New York: Viking Press, 1934.

DUGGER, W. Power: An institutional framework of analysis. Journal of Economic Issues, v. 14, n. 4, p. 897-907, 1980. 
DUGGER, W. Radical institutionalism: basic concepts. Review of Radical Political Economics, v. 20, n. 1, p. 1-20, 1988.

DUGGER, W. Emulation: an institutional theory of value formation. Review of Social Economy, v. 47, n. 2, p. 134-154, 1989.

DUGGER, W.; SHERMAN, H. Comparison of Marxism and institutionalism. Journal of Economic Issues, v. 28, n. 1, p.101-127, 1994.

DUGGER, W.; WALLER, W. Radical institutionalism: from technological to democratic instrumentalism. Review of Social Economy, v. 54, n. 2, p. 169-189, 1996.

FOSTER, J. F. John Dewey and economic value. Journal of Economic Issues, v. 15 , n. 4, p. 871-897, 1981a.

FOSTER, J. F. The relation between the theory of value and economic analysis. Journal of Economic Issues, v. 15, n. 4, p. 899-905, 1981 b.

GAMBS, J. Allan Gruchy and the association for evolutionary economics. In: ADAMS, J. (Org.). Institutional economics: essays in honor of Allan G. Gruchy. Boston: Martinus Nijhoff, 1980. p. 26-30.

GORDON, W. Institutionalized consumption patterns in underdeveloped countries. Journal of Economic Issues, v. 7, n. 2, p. 267-287, 1973.

HAMILTON, D. Institutions and technology are neither. Journal of Economic Issues, v. 20, n. 2, p. 525-532, 1986.

HAMILTON, W. The institutional approach to economic theory. American Economic Review, v. 9, n. 1, p. 309-318, 1919.

HICKERSON, S. R. Planning for institutional change in a complex environment: an approach and an application. Journal of Economic Issues, v. 17, n. 3, p. 631-665, 1983.

HODGSON, G. The approach of institutional economics. Journal of Economic Literature, v. 36, p. 166-192, 1998.

HODGSON, G. The evolution of institutions: an agenda for future theoretical research. Constitutional Political Economy, v. 13, n. 2, p. 111-127, 2002.

HODGSON, G. The evolution of institutional economics: agency, structure and Darwinism in American institutionalism. New York; London: Routledge, 2004a.

HODGSON, G. Reclaiming habits for institutional economics. Journal of Economic Psychology, v. 25, n. 4, p. 651-660, 2004b. 
JUNKER, L. The ceremonial-instrumental dichotomy in institutional analysis: the nature, scope and radical implications of the conflicting systems. American Journal of Economics and Sociology, v. 41, n. 2, p. 141-150, 1982.

JUNKER, L. The conflict between the scientific-technological process and malignant ceremonialism. American Journal of Economics and Sociology, v. 42, n. 3, p. 341-352, 1983.

KLEIN, P. Institutionalists, radical economists, and class. Journal of Economic Issues, v. 26, n. 2, p. 535-544, 1992.

LEE, F. A history of heterodox economics: challenging the mainstream in the twentieth century. Oxford: Routledge, 2009.

LOWE, A. What is evolutionary economics? Journal of Economic Issues, v. 14, n. 2, p. 247-254, 1980.

MAYHEW, A. Ayresian technology, technological reasoning, and doomsday. Journal of Economic Issues, v. 15, n. 2, p. 513-520, 1981.

MAYHEW, A. Culture: core concept under attack. Journal of Economic Issues, v. 21, n. 2, p.587-603, 1987.

MAYHEW, A. Waller on radical institutionalism: a comment. Journal of Economic Issues, v. 24, n. 3, p. 890-896, 1990.

O'HARA, P. Association for evolutionary economics and association for institutional thought. In: O'HARA, P. Encyclopedia of political economy. London: Routledge, 1995. p. 20-30.

O'HARA, P. A new measure of macroeconomic performance and institutional change: the index of community, warranted knowledge, and participation. Journal of Economic Issues, v. 31, n. 1, p. 103-129, 1997.

RUTHERFORD, M. Clarence Ayres and the instrumental theory of value. Journal of Economic Issues, v. 15, n. 3, p. 657-673, 1981.

RUTHERFORD, M. Thorstein Veblen and the process of institutional change. History of Political Economy, v. 16, n. 3, p. 331-334, 1984.

RUTHERFORD, M. Institutions in economics: the old and the new institutionalism. London: Cambridge University Press, 1994.

RUTHERFORD, M. Veblen's evolutionary programme: a promise unfulfilled. Cambridge Journal of Economics, v. 22, p. 463-477, 1998.

RUTHERFORD, M. American institutionalism after 1945: a research annual. Research in the History of Economic Thought and Methodology, v. 33, p. 95-123, 2015. 
SAMUELS, W. The case for methodological pluralism. In: SALANTI, A.; SCREPANTI, E. Pluralism in economics: new perspectives in history and methodology. Cheltenham, Brookfield: Edward Elgar, 1997.

SAMUELS, W. In (limited but affirmative) defense of Nihilism. Review of Political Economy, v. 5, n. 2, 2006.

SHIPMAN, A. Lauding the leisure class: symbolic content and conspicuous consumption. Review of Social Economy, v. 62, n. 3, p. 277-289, 2004.

STURGEON, J. I. The history of the association of institutional thought. Review of Institutional Thought, v. 1, n. 1, p. 40-53, 1981.

TOOL, M. (Org.). Evolutionary economics: foundation of institutional thought. New York: M. E. Sharpe, 1988a. v. 1.

TOOL, M. Evolutionary economics: foundation of institutional thought. New York: M. E. Sharpe, 1988b. v. 2.

VEBLEN, T. Why is economics not an evolutionary science. The Quarterly Journal of Economics, v. 12, n. 4, p. 373-397, 1898.

VEBLEN, T. The preconceptions of economic science I. The Quarterly Journal of Economics, v. 13, n. 4, p. 396-426, 1899a.

VEBLEN, T. The theory of leisure class. New York; Oxford: Oxford University Press, 2007 [1899b].

VEBLEN, T. The theory of business enterprise. Gloucester: Dodo Press, 2009 [1906].

VEBLEN, T. The limitations of marginal utility. Journal of Political Economy, v. 17, n. 9, p 620-636, 1909.

VEBLEN, T. Imperial Germany and the industrial revolution. New York: MacMillan, 1915.

VEBLEN, T. The higher learning in America. New York: B. W. Huebsch, 1918.

VEBLEN, T. The vested interests and the common man. New York: Cosimo, 2005 [1919].

WALLER, W. T., Jr. Ceremonial encapsulation and corporate cultural hegemony. Journal of Economic Issues, v. 21, n. 1, p. 321-327, 1987.

WALLER, W. T., Jr. Radical institutionalism: methodological aspects of the radical tradition. Journal of Economic Issues, v. 22, n. 3, p. 667-674, 1988.

WALLER, W. T., Jr. Avoiding the Cartesian vice in radical institutionalism: a reply to Mayhew. Journal of Economic Issues, v. 24, n. 3, p. 897-901, 1990. 
WHALEN, C. Wallace C. Peterson: a post-Keynesian institutionalist. Journal of Economic Issues, v. 50, n. 2, p. 584-593, 2016. 